\title{
Thyroid transcription factor 1 and Pax 8 synergistically activate the promoter of the human thyroglobulin gene
}

\section{R Espinoza, T L Schmitt and U Loos}

\author{
Department of Internal Medicine I, University Clinic of Ulm, D-89081 Ulm, Germany \\ (Requests for offprints should be addressed to U Loos, Department of Internal Medicine I, \\ Universitätsklinikum Ulm, Robert-Koch-Str. 8, 89081 Ulm, Germany; \\ Email: Ulrich.Loos@medizin.uni-ulm.de)
}

\begin{abstract}
Thyroglobulin $(\mathrm{Tg})$ is an essential thyroid-specific protein, which serves as the matrix for thyroid hormone biosynthesis. To obtain new insights in the regulation of $T g$ gene expression, we investigated the interaction of the human $T g$ promoter with the thyroid-specific transcription factors TTF-1 and Pax8. A reporter gene, containing a $202 \mathrm{bp}$ fragment from the human $\mathrm{Tg} 5^{\prime}$-flanking region including the promoter sequence and the transcriptional start site, and expression vectors containing the cDNAs for human TTF-1 and Pax8 were used in cotransfection experiments, in the non-thyroidal cell lines COS-7 and HeLa. Pax8 increased the specific transcriptional activity of the $T g$ promoter about threefold, whereas cotransfection with the homeodomain-containing protein TTF-1 stimulated promoter activity from six- to tenfold. The simultaneous expression of both factors stimulated the $T g$ promoter activity in a
\end{abstract}

multiplicative manner up to 25 -fold. TTF-1 binding sites could be localized precisely by lectron mobility shift assay. The two binding elements corresponded to sites $\mathrm{A}$ and $\mathrm{C}$ in the rat $T g$ promoter. Site-directed mutagenesis of three nucleotides in each binding element inhibited binding of TTF-1 to the two oligonucleotides. In cotransfection experiments, the mutant site $\mathrm{C}$ decreased TTF-1 transactivation to $26 \%$ of the wild-type, whereas an additional mutation in the site A reduced this value to almost zero, thus proving the physiological relevance of these sites. The present results demonstrate that the activity of the human $\mathrm{Tg}$ promoter is closely dependent on the function of TTF-1 and Pax8, opening the field for further investigations of pathological alterations of $T g$ gene expression.

Fournal of Molecular Endocrinology (2001) 27, 59-67

\section{INTRODUCTION}

Thyroglobulin ( $\mathrm{Tg})$, a protein specifically synthesised by the thyroid gland, is the large glycoprotein precursor of the thyroid hormones, thyroxine and tri-iodothyronine. Because expression of the $T g$ gene is observed only in normal thyroids and in a variety of thyroid tumors, serum $\mathrm{Tg}$ concentration is used to monitor for thyroid cancer recurrence and its metastases (Ringel et al. 1999). The expression of this gene is under the positive control of thyrotropin (thyroid stimulating hormone, TSH), which acts mainly via the intracellular messenger cAMP (Damante \& Di Lauro 1994).

The sequence of the promoter region from the $T g$ gene is known in different mammals, namely human, bovine, canine and rat (Christophe et al. 1985, 1989, Musti et al. 1987, Donda et al. 1991).
Studies in these species have shown that the region up to -200 nucleotides contains all the potential regulatory elements for thyroid-specific transcription (Donda et al. 1993). Although transiently transfected promoter sequences from the species indicated in the previous paragraph, when linked to reporter genes, exhibited equal activity after transfection into heterologous thyroid cells (Donda et al. 1993), mutagenesis experiments at homologous positions indicated that, despite the overall DNA sequence conservation, the molecular mechanisms involved in the control of $T g$ gene expression have evolved differently within mammals (Donda et al. 1991, 1993). Understanding of these mechanisms has allowed the rat $T g$ promoter to be used for an in vitro suicide gene/prodrug therapy in an animal model of differentiated thyroid carcinomas (Braiden et al. 1998, Nagayama et al. 1999). 
The control of gene expression depends largely on the binding of transcription factors on promoter sequences. In thyroid follicular cells, three transactivators have been described: thyroid transcription factor 1 (TTF-1), thyroid transcription factor 2 (TTF-2) and the paired-domain transcription factor (Pax8), which regulate the transcriptional activity of $\mathrm{Tg}$ and other thyroid-specific genes, such as thyroperoxidase $(T P O)$ and thyrotropin receptor (TSHr) (Damante \& Di Lauro 1994).

In addition to their expression in the follicular thyroid cells, TTF-1 and Pax8 are also expressed in the lung and kidney respectively. However, the two factors are present together only in the thyroid follicular cell, suggesting that this unique combination could have a role in the expression of the thyroid-specific phenotype (Fabbro et al. 1994).

The functional roles of TTF-1 and Pax 8 binding sites have been studied in rat and bovine $T g$ gene promoters (Zannini et al. 1992, Fabbro et al. 1998, Javaux et al. 1992), but the roles of both human transcription factors have not been characterized in human $\mathrm{Tg}$ promoter, even though the cDNA sequences from human TTF-1 and Pax 8 are known (Poleev et al. 1995, Saiardi et al. 1995).

The aim of this study was to gain insight into the cellular regulation of the human $\mathrm{Tg}$. In the present work, we give, through comprehensive analyses, the first functional demonstration that the human $\mathrm{Tg}$ gene is regulated by TTF1 and Pax 8 proteins.

\section{MATERIALS AND METHODS}

\section{Construction of reporter genes and expression vectors}

The promoter region from the human $T g$ gene was amplified from human genomic DNA with the Advantage Genomic Polymerase Mix (Clontech, Heidelberg, Germany), using the forward primer 5'-ATCCTCTAGCTCCACTGGCCACACG and the reverse primer $5^{\prime}$-AGGAAGGAGGAGAAAC CACTGCTTGC, the sequences of which were taken from Christophe et al. (1985). The resulting $202 \mathrm{bp}$ product extended from nt -180 to +22 relative to the transcription start. The PCR product was ligated into the $\mathrm{T} / \mathrm{A}$ cloning vector $\mathrm{pCR} 2 \cdot 1$ from Invitrogen (Groningen, The Netherlands) and eight positive clones were sequenced using the T7 primer. All clones showed sequence identity to the published sequence (Christophe et al. 1985). Subsequently, a XbaI/BamHI-fragment was cut out and ligated into the NheI/BglII- site of pGL3-Basic (Promega, Mannheim, Germany) resulting in pGL-Tg202.
Mutations in the reporter gene vector pGLTg202 were introduced by a two-step PCR method. First, two mutant overlapping inner primers were synthesized (see Fig. 5), which were used in a first $\mathrm{PCR}$ reaction together with the corresponding outer primers (forward primer 5'-CTCTTACGCGTGC TAGATGCATGC and the reverse primer $5^{\prime}$-ATG CCAAGCTTACTTAGATCGCAGA). The mutation was designed in such a way that it produced a novel restriction site. The two products of the first PCR were digested with the corresponding restriction enzyme and ligated; subsequently, a second PCR was performed with the outer primers only. The product from the second PCR was again digested with MluI and HindIII and ligated into the pGL-Tg202, from which the corresponding fragment had been cut out. All mutations were confirmed by sequencing.

The plasmid H8, containing the full-length cDNA for human Pax8, was obtained from Dr Gruss (Poleev et al. 1992). A NaeI/SmaI-fragment of $1793 \mathrm{bp}$ was ligated into the expression vector pCI (Promega), which was digested with SmaI, resulting in pCI-Pax8.

The pCI-TTF-1 expression vector was generated by cloning the SspI/DraI fragment $(1423 \mathrm{bp})$ from the pBKRSV-6A2 vector into the SmaI site of the pCI expression vector. The pBKRSV-6A2, containing the full-length human cDNA for TTF-1 $(\mathrm{Nkx} 2 \cdot 1)$ was kindly provided by $\mathrm{Dr} \mathrm{P}$ Minoo (Hamdan et al. 1998).

\section{Cell culture and transfection assays}

HeLa and COS-7 cell lines were obtained from the Deutsche Sammlung von Mikroorganismen und Zellkulturen and grown in DMEM (Gibco), supplemented with $10 \%$ fetal bovine serum (Gibco) and the antibiotic, gentamycin (Gibco). FRTL-5 rat thyroid cells were obtained from the European Collection of Cell Cultures and cultured as described (Behr et al. 1998). All cells $\left(2 \times 10^{5}\right)$ were seeded in 12 -well plates $24 \mathrm{~h}$ before transfection. HeLa and COS-7 cells were transiently transfected using the Superfect reagent (Qiagen, Hilden, Germany) according to the instructions of the manufacturer. Each reaction contained $1 \mu \mathrm{g}$ respective luciferase vector, $0 \cdot 2 \mu \mathrm{g}$ expression plasmid (pCI, pCI-Pax8, or pCI-TTF-1) and $6 \mu$ l Superfect reagent in a total volume of $500 \mu \mathrm{l}$ per well. When Pax 8 and TTF-1 were transfected together, we used $0.4 \mu \mathrm{g}$ pCI (control plate) or $0.2 \mu \mathrm{g}$ pCI-Pax 8 plus $0 \cdot 2 \mu \mathrm{g}$ pCI-TTF-1 (test plate).

FRTL-5 cells were transfected by using the Effectene reagent (Qiagen). Only the use of this reagent achieved high transfection efficiencies in 
that cell line. Each reaction contained $0.5 \mu \mathrm{g}$ respective luciferase vector, $12 \mu \mathrm{l}$ Enhancer and $15 \mu \mathrm{l}$ Effectene reagent in a total volume of $484 \mu \mathrm{l}$ per well. After transfection, cells were incubated for $40 \mathrm{~h}$. Cell extract preparations and luciferase assays were carried out as described previously (Schmitt et al. 2000). For normalization of the luciferase activities, we measured protein content in each well by the BioRad protein assay. To exclude nonspecific effects in the cotransfection studies, the empty pCI expression vector was used for comparison and all luciferase activity values were referred to the underlying Basic vector. Experiments were performed three to four times in triplicate, and the data represent mean values \pm S.D.

\section{Nuclear extracts}

Nuclear extracts were made from HeLa cells (from normal and transfected cells with pCI-TTF-1 or pCI-Pax8 expression vector) by a modification of the method of Dignam et al. (1983). For each preparation, $4 \times 100 \mathrm{~mm}$ diameter dishes were used. All procedures were carried out at $4{ }^{\circ} \mathrm{C}$.

Cells were washed with ice-cold PBS and scraped off in $1.5 \mathrm{ml}$ PBS. After centrifugation for $10 \mathrm{~min}$ at 3800 r.p.m., the cell pellet was vortexed for 30 s, suspended in $1 \mathrm{ml}$ Dignam's A buffer containing $0.5 \%$ IGEPAL (Sigma) and $0.3 \mathrm{M}$ sucrose and allowed to stand on ice for $10 \mathrm{~min}$. To release nuclei, cells were frozen and thawed once and then vortexed for $30 \mathrm{~s}$, followed by homogenization in an all-glass Dounce homogenizer (Wheaton pestle B, 10-15 strokes).

The cell lysate was centrifugated at 6000 r.p.m. for $10 \mathrm{~min}$, and the pellet was suspended in $1.5 \mathrm{ml}$ Dignam's A buffer (containing 0.5\% IGEPAL and $0 \cdot 3 \mathrm{M}$ sucrose), vortexed for $30 \mathrm{~s}$ and overlaid on $0.5 \mathrm{ml}$ Dignam's A buffer containing $1.5 \mathrm{M}$ sucrose. After centrifugation for $1 \mathrm{~h}$ at $20800 \mathrm{~g}$, the crude nuclear pellet was resuspended in $250 \mu \mathrm{l}$ Dignam's $\mathrm{C}$ buffer, vortexed for $30 \mathrm{~s}$, allowed to stand on ice for $20 \mathrm{~min}$ and homogenized in an Douce homogenizer (five strokes). The resulting suspension was tumbled for $30 \mathrm{~min}$ and then centrifuged for $30 \mathrm{~min}$ at $20800 \mathrm{~g}$. The clear supernatant was concentrated in Microcon-10 (Amicon, USA). Together with the concentration of the sample, the buffer $\mathrm{C}$ was exchanged for that of Dignam's D buffer. The sample was divided into small aliquots and stored at $-80^{\circ} \mathrm{C}$.

\section{Electro mobility shift assay}

For delineation of binding-sites, we used electro mobility gel-shift assays (EMSA). Complementary
-180 ATCCTCTAGCTCCACTGGCCACACGAGTGCCCTCAGGAGG TgOLA

-140 AGTAGACACAGGTGGAGGGAGCTCCTTTTGACCAGCAGAG TgOIB

-100 AAAACAGGATGGGGCACTGCCTCACTGAGGACCTGGGGGT TgOIC

FIGURE 1. Sequence of the first 120 nucleotides from the cloned $\mathrm{Tg}$ promoter fragment. The sequences of the oligonucleotides TgOLA, TgOLB and TgOLC are underlined. Numbering is relative to the transcriptional start site, which is assigned +1 .

oligonucleotides (obtained from Interactiva, Ulm, Germany) were annealed and a single $5^{\prime}$-overhang $\mathrm{T}$ was filled with $\left[{ }^{35} \mathrm{~S}\right] \mathrm{dATP}$ using Klenow fragment. The reaction was then heated to $75^{\circ} \mathrm{C}$ and purified onto gel filtration columns (Roche, Mannheim, Germany). The sequence of the oligonucleotides from the $T g$ promoter region (TgOLA, TgOLB and TgOLC) is shown in Fig. 1. The sequence of the oligonucleotide from the TPO promoter region (TPOLB) is 5'-TCAGGACACACAAGAGGCC CGGCGC (Abramowicz et al. 1992). The binding reaction consisted of $0.2 \mathrm{pmol}$ labeled doublestranded oligonucleotide, $1-1 \cdot 5 \mu \mathrm{l}$ nuclear extract (from normal and transfected cells with pCI-TTF-1 or pCI-Pax8 expression vector) in a total volume of $10 \mu \mathrm{l}$. Binding buffer was $15 \mathrm{mM}$ Tris- $\mathrm{HCl}, \mathrm{pH} 7 \cdot 6$, $50 \mathrm{mM} \mathrm{KCl}, 10 \%$ glycerol, poly dI-dC at $100 \mu \mathrm{g} / \mathrm{ml}$. As specific competitors, unlabeled oligonucleotides were used. After $25 \mathrm{~min}$ at room temperature, the entire reaction was loaded onto a $6 \%$ polyacrylamide gel and run in precooled $0 \cdot 5^{\prime}$ TBE buffer $(45 \mathrm{mM}$ Tris, borate, EDTA). The gel was fixed, dried and exposed to X-ray film.

\section{RESULTS}

\section{Transactivation of $\boldsymbol{T g}$ gene promoter by TTF-1 and Pax8}

A 202 bp fragment from the human $T g 5^{\prime}$-flanking region including the promoter sequence was cloned by PCR from genomic DNA and was fused to a luciferase reporter gene, resulting in pGL-Tg202. When transfections with this construct were performed in the non-thyroidal cell lines HeLa and COS-7, transcriptional activity was not greater than that of the underlying promoterless Luc vector pGL3-Basic, but it was active in FRTL-5, a rat thyroid cell line, proving that $T g$ promoter is active only in thyroid follicular cells (Fig. 2).

In order to investigate the functional role of the thyroid-specific transcription factors TTF-1 and 


\section{Activity of the wt-Tg promoter in thyroidal and non thyroidal cell lines}

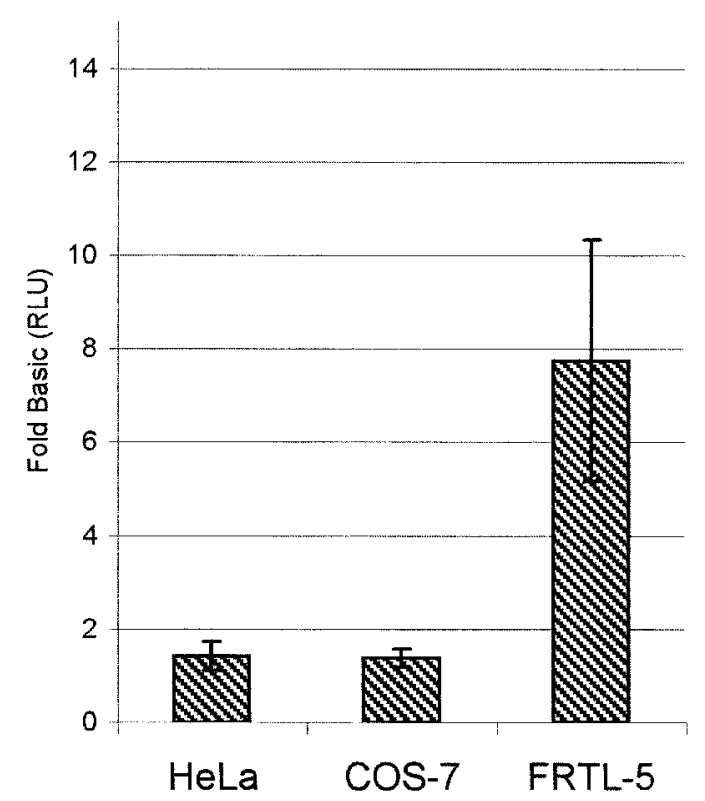

FIGURE 2. Summary of the transfection assays in HeLa, COS-7 and FRTL-5 cells. pGL-Tg202 was transiently transfected in each cell line as described in Materials and Methods. Cells were harvested $40 \mathrm{~h}$ later and assayed for luciferase activity. After correction for protein content, all Luc values were referred to the empty Luc vector pGL3-Basic, which was included in each experiment. The values represent the means \pm s.D. of three to five experiments performed in triplicate. wt, wild-type; RLU, relative light units.

Pax8 in the control of the expression of the human Tg gene, HeLa and COS-7 cells were cotransfected with pGL-Tg202 and either pCI-TTF-1 or pCI-Pax8 - two expression vectors containing the human TTF-1 and Pax8 cDNAs respectively under the control of the human cytomegalovirus promoter. The expression of both genes was proved by RT-PCR and gel-shift analyses (data not shown).

The presence of TTF-1 increased the $T g$ promoter activity by about tenfold in HeLa cells and sixfold in COS-7 cells (Fig. 3). However, the paired-domain factor Pax8 showed a lower transactivation of the $T g$ promoter, this reached about threefold in both cell lines. When both transcription factors were transfected together, the transcriptional activity was stimulated in a multiplicative manner by a factor between 15 and 25 in COS- 7 and HeLa respectively (Fig. 3).

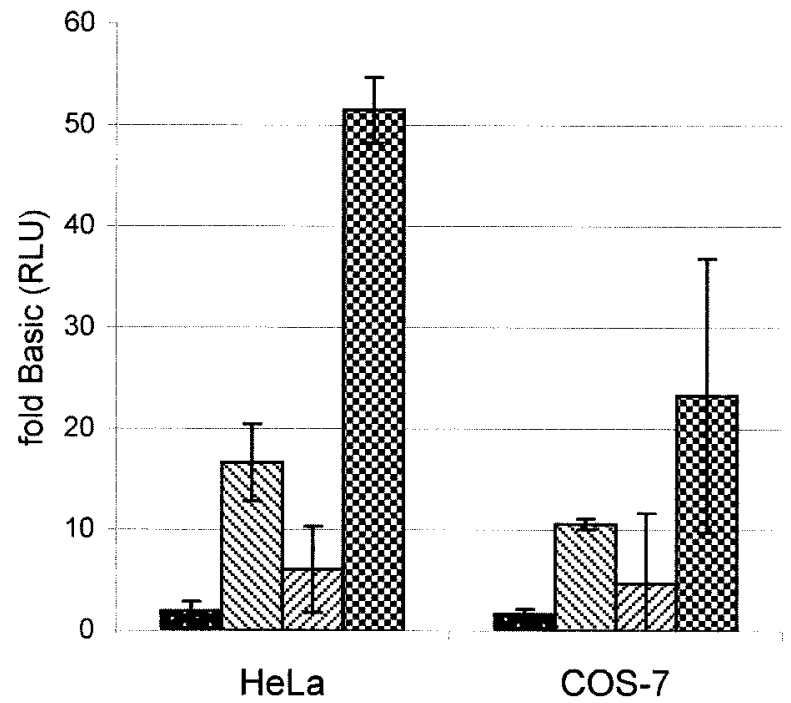

FIGURE 3. Summary of the cotransfection assays in HeLa and COS-7 cells. pGL-Tg202 was transfected in both cell lines together with pCI alone $(\mathrm{Co})$, pCI-TTF-1, pCI-Pax8 and both TTF-1 and Pax8 as described in Materials and Methods. Cells were harvested $40 \mathrm{~h}$ later and assayed for luciferase activity. After correction for protein content, all Luc values were referred to the empty Luc vector $\mathrm{pGL}$-Basic, which was included in each experiment. The values represent the means \pm S.D. of three to five experiments performed in triplicate.

\section{DNA binding assay}

Sequence analysis revealed several putative binding sites for TTF-1 and Pax8 in the $T g$ promoter region, the location of which is conserved through several species (Fig. 1). Because TTF-1 had a much stronger impact on $\mathrm{Tg}$ promoter function, we focused our work on the localization of its binding sites. We examined first the sites $\mathrm{B}$ and $\mathrm{C}$, which showed great homology to the consensus sequence, and compared them with the known TTF-1 binding sites from the human thyroperoxidase (TPO) promoter (Abramowicz et al. 1992). As is seen in Fig. $4 A$, site $\mathrm{C}$ produced a strong shift with the nuclear extract from TTF-1 transfected cells, which is comparable to the TPO element. Site B did not bind TTF-1. Subsequently, site $\mathrm{C}$ and also site A were examined more closely by the inclusion of a 'cold' mutant oligonucleotide, in which three nucleotides in the central core sequence were changed (Figs $4 B$ and 5). The inability of the mutated oligonucleotides to compete for binding 


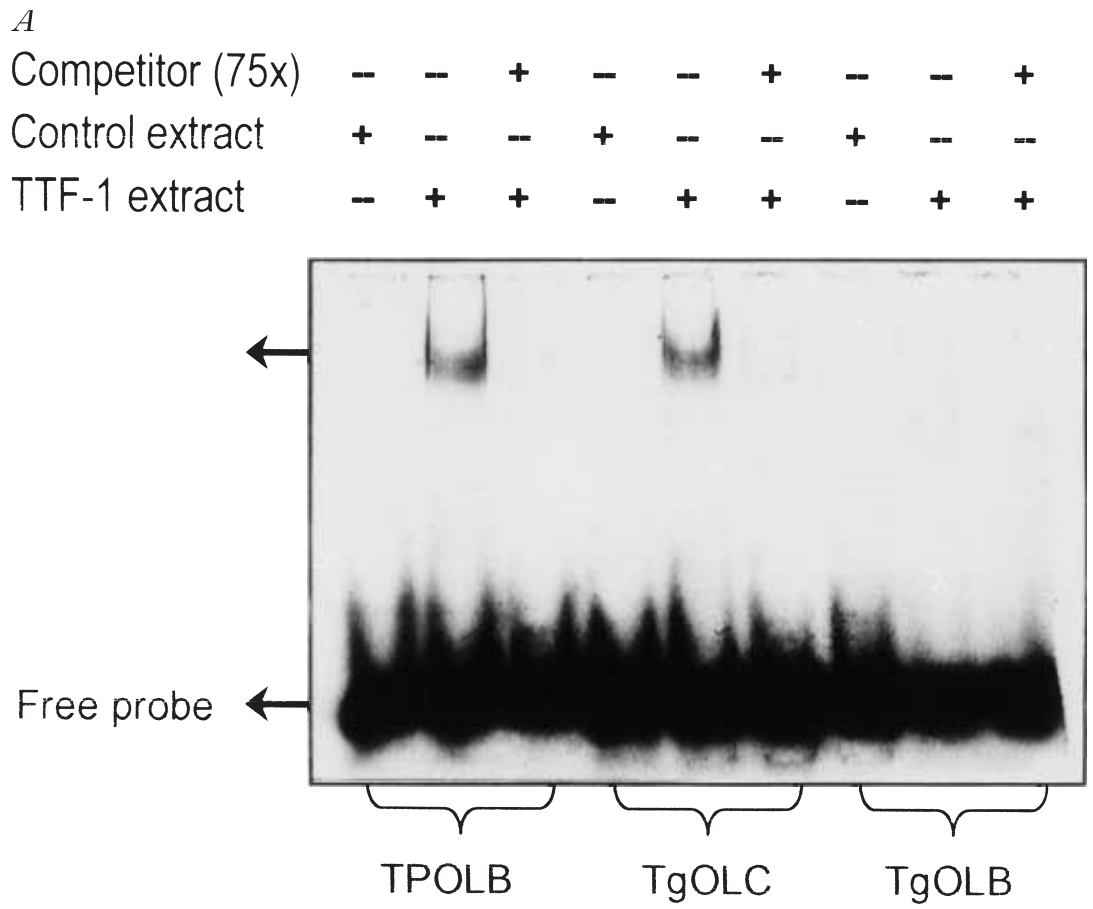

$B$

Tg-OLC

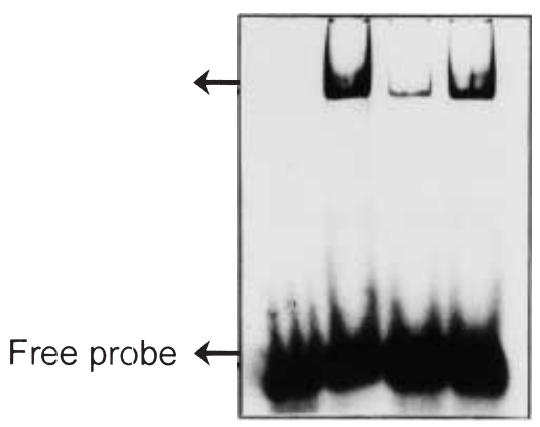

TTF-1 extract

$\operatorname{Tg}-\mathrm{OLC}(75 \mathrm{x})^{\star}$

mt-OLC $(75 x)^{*}$

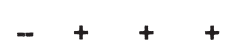

$-++$

$-\quad-\quad+$

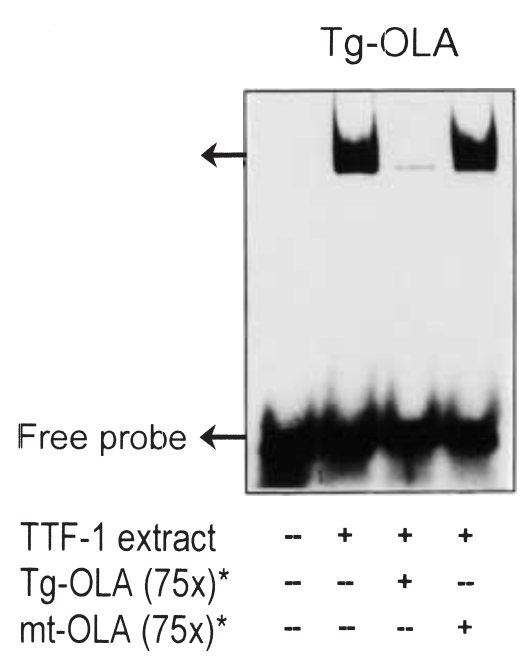

Tg-OLA

Figure 4. Gel-shift analysis with TTF-1. $(A)$ We incubated $0 \cdot 25$ pmol radioactively labeled oligonucleotides from the $T g$ promoter (TgOLB and TgOLC) or from the TPO promoter (TPOLB) with $2 \mu \mathrm{g}$ nuclear extract from HeLa cells transfected with pCI alone (control extract) or pCI-TTF-1. When indicated, a 75-fold excess of the respective unlabeled oligonucleotide was added. Arrows indicate the position of free and bound oligo on the autoradiograph. $(B)$ Detailed gel-shift analysis using TgOLC (left) and TgOLA (right) with TTF-1. The oligos were incubated with $2 \mu \mathrm{g}$ TTF-1 extract from COS-7 cells in the absence or presence of unlabeled competitor or mutant competitor, where indicated (*). The sequence of the mutant $(\mathrm{mt})$ oligonucleotides is given in Fig. 5. 


\section{mtolA $---------C T A-------$ TgOlA TGGCCACACGAGTGCCCTCA II | || | \\ Consensus TTF-1 ACTCAAGT \\ TgOlC \\ | || | | \\ mtolc TGCCTCACTGAGGACCTGGGGG}

FIgURE 5. Sequence alignment of TgOLA and TgOLC with the consensus sequence for TTF-1 binding elements. Above TgOLA and below TgOLC are shown the mutated nucleotides introduced for gel-shifts and for reporter gene constructs.

proved the specificity of the interaction and defined the residues required for binding. Figure 5 displays the sequence of normal and mutated oligonucleotides, which are compared with the sequence of consensus TTF-1 binding elements. These data were fully supported by DNase footprinting assays in which two regions, corresponding to the sites $\mathrm{A}$ and $\mathrm{C}$, were protected by bacterially expressed TTF-1 protein (data not shown). In these experiments, Pax 8 did not reveal any binding site (data not shown). Also, Pax8 did not bind in EMSAs to any of the oligonucleotides $\mathrm{A}, \mathrm{B}$ or $\mathrm{C}$, either alone or in the presence of cotransfected TTF-1 (data not shown).

\section{TTF1-transactivation by reporter gene mutants}

On the basis of the binding assay results, functional analysis of mutated TTF-1 binding sites A and C was carried out. First, three nucleotides in the site $\mathrm{C}$ of pGL-Tg202, which are necessary for binding, were changed. Cotransfection studies in HeLa and COS-7 cells with this mutant construct (pGLTg202-mutC) and pCI-TTF-1 showed a reduction to $26 \%$ of the transactivation observed normally (Fig. 6). In addition, three nucleotides in the site A were mutated accordingly (pGL-Tg202-mutA+C), which further decreased the TTF-1 transactivation to less than $10 \%$ of the wild-type value in HeLa cells and completely abolished it in COS-7 cells (Fig. 6). Conversely, we found that the mutant construct pGL-TgmutA+C decreased the Pax 8 transactivation to $15 \%$ and $35 \%$ in HeLa and COS-7 respectively, in relation to the wild-type reporter vector pGL-Tg202. Similar results, as in comparison with mutation $\mathrm{A}+\mathrm{C}$, were obtained when only the site A (pGL-Tg mutA) was mutated, which decreased the TTF- 1 and $\operatorname{Pax} 8$ transactivation to $10 \cdot 59 \%$ and $15 \cdot 59 \%$ of the wild-type value in HeLa cells, respectively.
TTF-1 transactivation of mutants

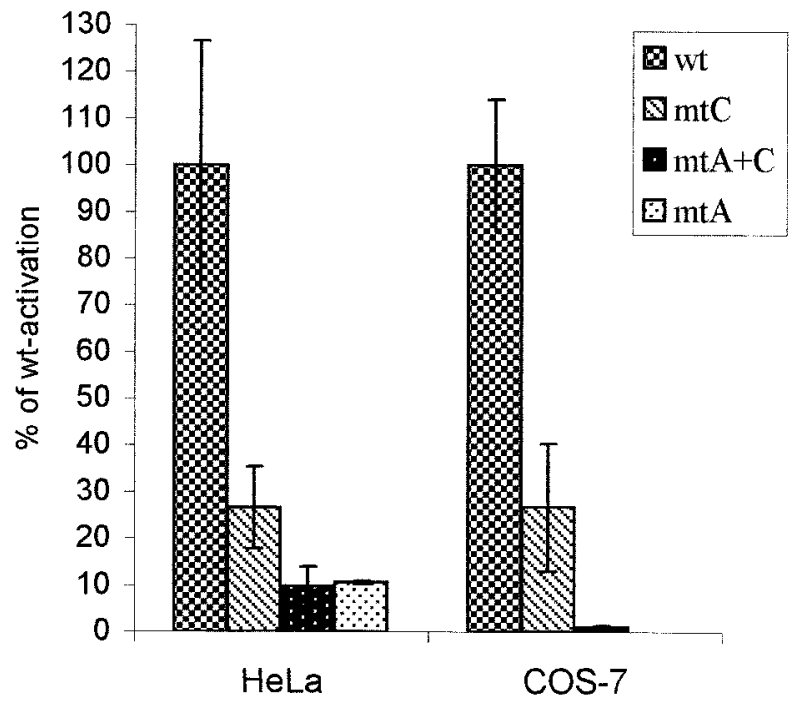

FIGURE 6. Influence of mutations (mt) on TTF-1 transactivation. pGL-Tg202 (wild-type, wt) and the mutations $\mathrm{C}, \mathrm{A}+\mathrm{C}$ and $\mathrm{A}$ were transfected in HeLa or COS-7 cells together with the expression vector pCI-TTF-1. The mutant construction A was only transfected in HeLa cells. The values represent percentage activation levels of wild-type, which was set to $100 \%$ (corresponding to $8 \cdot 8$ - or $5 \cdot 8$-fold activation, in HeLa and COS-7 respectively); an activation of onefold was assigned $0 \%$. The values represent the means \pm s.D. of three to five experiments performed in triplicate.

The mutant constructions $(\mathrm{A}, \mathrm{C}$ and $\mathrm{A}+\mathrm{C}$ ) were used in transfection experiments in FRTL-5, a rat thyroid cell line that has endogenous TTF-1 and Pax8 proteins (Rossi et al. 1995). Interestingly, only mutation in the site A showed decreased activity in comparison with the wild-type value (Fig. 7).

Taken together, these results prove that the sites $\mathrm{A}$ and $\mathrm{C}$ are responsible for the TTF-1 and Pax 8 transactivation of the human $T g$ promoter, and suggest the participation of both sites during $\mathrm{Tg}$ activation.

\section{DISCUSSION}

To understand the cellular regulation of the human $T g$ gene, we investigated the transactivation of its promoter by the thyroid-specific transcription factors TTF-1 and Pax8. Similar analyses have been performed in the rat (Zannini et al. 1992, Fabbro et al. 1998) and bovine (Javaux et al. 1992), but not in the human, $T g$ gene. With respect to the 
Activity of mutant $\mathrm{Tg}$ promoter constructions in FRTL-5

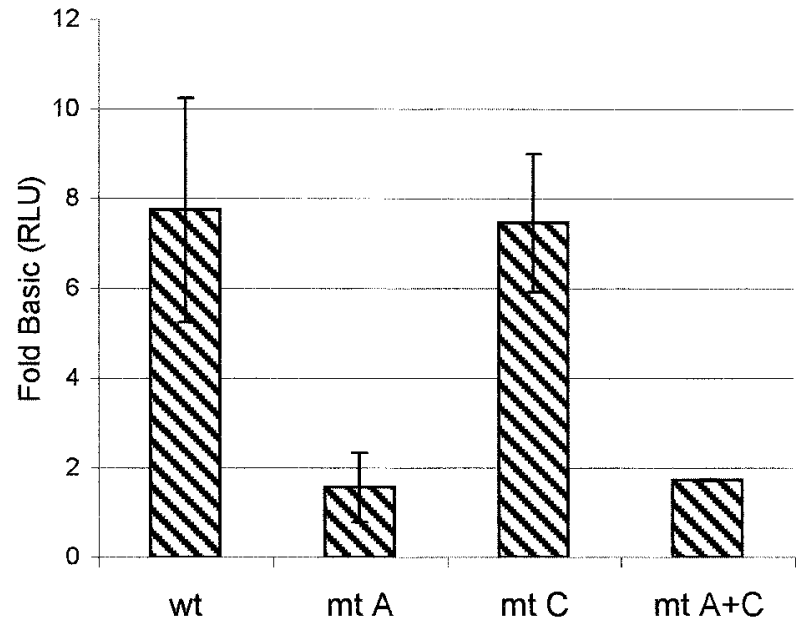

FIgURE 7. Activity of the mutant $T g$ promoter constructions (A, C and A+C) in FRTL-5 cells. The mutant $(\mathrm{mt})$ constructions $(\mathrm{A}, \mathrm{C}$ and $\mathrm{A}+\mathrm{C})$ were used in transfection experiments in FRTL-5 as described in Materials and Methods. Cells were harvested $40 \mathrm{~h}$ later and assayed for luciferase activity. After correction for protein content, all Luc values were referred to the empty Luc vector pGL3-Basic, which was included in each experiment. The values represent the means \pm S.D. of three to five experiments performed in triplicate. wt, wild-type.

human gene, there is only one functional study of the human $T g$ promoter activity, which could be demonstrated only in the presence of forskolin (Donda et al. 1993). Generally, mutagenesis experiments at homologous positions in four $\mathrm{Tg}$ promoters (from cattle, rat, man and dog) indicated that, despite the overall DNA sequence conservation, the molecular mechanisms involved in the control of $T g$ gene expression have evolved differently within mammals (Donda et al. 1991, 1993). In other words, the isolated changes accumulated during evolution result in different behaviors of the $T g$ promoters, when subjected to equivalent mutagenesis.

We used a homologous system, performing the transfections in human or simian cells and using expression vectors containing the cDNAs for human TTF-1 and Pax8 respectively. The data obtained in this work proved the tight regulation of the $T g$ gene, the promoter activity of which in non-thyroid cells is entirely dependent on the two transcription factors under study. This finding is in agreement with those of studies performed on rat $T g$ promoter (Zannini et al. 1992, De Felice et al. 1995) except for one case in which TTF-1 appeared to reduce the activity of this promoter (Fabbro et al. 1998). Acebron et al. (1995) have reported low levels of $T g$ mRNA in a patient with congenital hypothyroidism who lacked expression of TTF-1, which correlates well with our results. Because of the much stronger impact of TTF-1 on $T g$ promoter activity, we determined its binding sites by EMSA. Two sites, corresponding to the sites A and $\mathrm{C}$ in the rat $T g$ promoter, were found to bind TTF-1, whereas the middle site $\mathrm{B}$ did not bind. This result is in contrast to those from studies performed on rat and bovine $T g$ promoters, in which TTF-1 recognized three sites (A, B and C) in both promoters (Javaux et al. 1992). Another difference between human and rat is that Pax 8 did not bind to any of the three sites investigated in the present study, whereas in the rat both TTF-1 and Pax8 bind to the same site C (Zannini et al. 1992). These EMSA data were fully supported by DNase footprinting assays, in which two regions, corresponding to the sites $\mathrm{A}$ and $\mathrm{C}$, were protected by bacterially expressed TTF-1 protein. A similar situation has been found in studies using the human NIS promoter, in which, despite threefold stimulation by $\operatorname{Pax} 8$, no binding site could be located, suggesting an indirect mode of action with the participation of other proteins (Schmitt et al. 2001). Putative binding sites for TTF-1 have until now been identified only in the human $T g$ enhancer, which is located between -3.2 and $-2.7 \mathrm{~kb}$ from the transcriptional start site (Berg et al. 1996).

In the present work, mutations in both sites $\mathrm{A}$ and C of the human $\mathrm{Tg}$ promoter not only abolished TTF-1 transactivation, but also showed decreased Pax 8 activation in cotransfection assays, underlining the close interplay of these two transcription factors. The general arrangement of two functional TTF-1 binding sites is found in the promoters of thyroidspecific genes (Damante \& Di Lauro 1994), and in lung-specific genes such as surfactant proteins A, B and C (Bruno et al. 1999, Margana et al. 2000, Kelly et al. 1996). In these genes, TTF-1 is not only important for basal activity, but also participates during cAMP induction of gene expression (Li et al. 1998). TTF-1 is expressed in the thyroid, and in certain areas of the brain and especially in lung tissue; in the last of these it serves increasingly as an immunohistochemical marker for differentiating pulmonary carcinomas (Khoor et al. 1999, Ordonez 2000). The synergistic functional interplay of TTF-1 and Pax8 reported in the present study has been exploited in a preliminary gene therapy in which the overexpression of both transcription factors restored the rat $T g$ gene promoter activity in two thyroid carcinomas cell lines (Chun et al. 1998). In contrast, TTF-1 was able to induce $T g$ gene 
expression in FR'T cells - a rat undifferentiated thyroid cell line (Mascia et al. 1997). Like TTF-1, Pax8 expression is not confined to the thyroid, but has been found in the developing kidney and some areas of the brain also (Zannini et al. 1992). Recently, Ros and his colleages (1999) reported that TTF-1 and Pax 8 were expressed in well differentiated thyroid adenomas and that their expression decreased in less differentiated papillary and follicular carcinomas and was lost in undifferentiated anaplastic carcinomas. Also, they affirmed that the expression of the thyroid specific genes $T g, T P O$ and $T S H r$ and their transcription factors, TTF-1 and Pax8, was lost in thyroid cells derived from follicular papillary and anaplastic human carcinomas. Fabbro et al. (1994) found that, in anaplastic thyroid carcinomas, the absence of TTF-1 was associated with the absence of $T g$ gene expression. This finding indicated, in agreement with our report, that TTF-1 is a factor necessary for the expression of the thyroid differentiated phenotype. On the basis of our results, using a rat thyroid cell line as a model of study, the integrity of the site $\mathrm{A}$ and not of the site $\mathrm{C}$ appears to be functionally essential to sustain normal activity of the human $T g$ promoter. This observation contrasts with those made by Sinclair et al. (1990) and Javaux et al. (1992), who found that, in rat and bovine promoters, mutations in the regions $\mathrm{A}$ and $\mathrm{C}$ respectively affected the promoter activity.

Our data support the notion that one should not over-generalize the data on $T g$ promoter architecture as determined in a given species, as there are differences in the molecular interactions involved in the promoter function. In any case, a functional assay of the human $T g$ promoter mutants in human thyroid cells will be required to clarify the importance of the integrity of the site A.

In the present study, we give, through comprehensive analyses, the first functional demostration that the activity of the human $T g$ promoter is closely dependent on the function of TTF-1 and Pax8, opening the field for further investigations of pathological alterations in $T g$ gene expression.

\section{ACKNOWLEDGEMENTS}

The authors wish to thank Dr P Gruss (Max-Planck-Institute of Biophysical Chemistry, Göttingen) for kindly providing us with the Pax8 cDNA clone and $\operatorname{Dr} \mathrm{P}$ Minoo (University of Southern California, School of Medicine, Los Angeles, USA) for the gift of TTF-1 cDNA. We are grateful to Professor R Di Lauro and Dr Stella Zannini for helping us with the DNase I footprinting assays, which were carried out in their laboratory. This work was supported by a grant from the Deutsche Forschungsgemeinschaft (DFG, Lo 291/5-2).

\section{REFERENCES}

Abramowicz MJ, Vassart G \& Christophe D 1992 Functional study of the human thyroid peroxidase gene promoter. European Fournal of Biochemistry 203 467-473.

Acebron A, Aza-Blanc P, Rossi DL, Lamas L \& Santisteban P 1995 Congenital human thyroglobulin defect due to low expression of the thyroid-specific transcription factor TTF-1. Fournal of Clinical Investigation 96 781-785.

Behr M, Schmitt TL, Espinoza CR \& Loos U 1998 Cloning of a functional promoter of the human sodium/iodide-symporter gene. Biochemical Fournal 331 359-363.

Berg V, Vassart G \& Christophe D 1996 Identification of a thyroid-specific and cAMP-responsive enhancer in the upstream sequences of the human thyroglobulin promoter. Biochimica et Biophysica Acta 1307 35-38.

Braiden V, Nagayama Y, Iitaka M, Namba H, Niwa M \& Yamashita S 1998 Retrovirus-mediated suicide gene/prodrug therapy targeting thyroid carcinoma using a thyroid-specific promoter. Endocrinology 139 3996-3999.

Bruno MD, Whitsett JA, Ross GF \& Korfhagen TR 1999 Transcriptional regulation of the murine surfactant protein-A gene ba B-Myb. Fournal of Biological Chemistry 274 27523-27528.

Christophe D, Cabrer B, Bacolla A, Targovnik H, Pohl V \& Vassart G 1985 An unusually long poly (purine)-poly (pyrimidine) sequence is located upstream from the human thyroglobulin gene. Nucleic Acids Research 13 5127-5144.

Christophe D, Gérard C, Juvenal E, Ledent C, Christophe-Hobertus C, Dumont JE \& Vassart G 1989 Identification of a cAMP-responsive region in thyroglobulin gene promoter. Molecular and Cellular Endocrinology 64 5-18.

Chun YS, Saji M \& Zeiger MA 1998 Overexpression of TTF-1 and Pax-8 restores thyroglobulin gene activity in ARO and WRO cell lines. Surgery 124 1100-1105.

Damante G \& Di Lauro R 1994 Thyroid-specific gene expression. Biochimica et Biophysica Acta 1218 255-266.

De Felice M, Damante G, Zannini M, Francis-Lang H \& Di Lauro R 1995 Redundant domains contribute to the transcriptional activity of the thyroid transcription factor 1 . Fournal of Biological Chemistry 270 26649-26656.

Dignam JD, Lebovitz RM \& Roeder RG 1983 Accurate transcription initiation by RNA polymerase II in a soluble extract from isolated mammalian nuclei. Nucleic Acids Research 11 1475-1489.

Donda A, Vassart G \& Christophe D 1991 Isolation and characterization of the canine thyroglobulin gene promoter region. Biochimica et Biophysica Acta 1090 235-237.

Donda A, Javaux F, Van Renterghem P, Gervy-Decoster C, Vassart G \& Christophe D 1993 Human, bovine, canine and rat thyroglobulin promoter sequences display species-specific differences in an in vitro study. Molecular and Cellular Endocrinology 90 23-26.

Fabbro D, Di Loreto C, Beltrami CA, Belfiore A, Di Lauro R \& Damante G 1994 Expression of thyroid-specific transcription factors TTF-1 and Pax- 8 in human thyroid neoplasms. Cancer Research 54 4744-4749.

Fabbro D, Pellizzari L, Mercuri F, Tell G \& Damante G 1998 Pax-8 protein levels regulate thyroglobulin gene expression. fournal of Molecular Endocrinology 21 347-354. 
Hamdan H, Liu H, Li C, Jones C, Lee M, deLemos R \& Minoo P 1998 Structure of the human Nkx2.1 gene. Biochimica et Biophysica Acta 1396 336-348.

Javaux F, Bertaux F, Donda A, Francis-Lang H, Vassart G, Di Lauro R \& Christophe D 1992 Functional role of TTF-1 binding sites in bovine thyroglobulin promoter. FEBS Letters 300 222-226.

Kelly SE, Bachurski CJ, Burhans MS \& Glasser SW 1996 Transcription of the lung-specific surfactant protein $\mathrm{C}$ gene is mediated by thyroid transcription factor 1 . Fournal of Biological Chemistry 271 6881-6888.

Khoor A, Whitsett JA, Stahlman MT, Olson SJ \& Cagle PT 1999 Utility of surfactant protein B precursor and thyroid transcription factor 1 in differentiating adenocarcinoma of the lung from malignant mesothelioma. Human Pathology 30 $695-700$

Li J, Gao E \& Mendelson CR 1998 Cyclic AMP-responsive expression of the surfactant protein-A gene is mediated by increased DNA binding and transcriptional activity of thyroid transcription factor 1. Fournal of Biological Chemistry 273 4592-4600.

Margana R, Berhane K, Alam MN \& Boggaram V 2000 Identification of functional TTF-1 and Sp1/Sp3 sites in the upstream promoter region of rabbit SP-B gene. American Fournal of Physiology - Lung Cellular and Molecular Physiology 278 L477-L484.

Mascia A, De Felice M, Lipardi C, Gentile R, Calì G, Zannini M, Di Lauro R \& Nitsch L 1997 Transfection of TTF-1 gene induces thyroglobulin gene expression in undifferentiated FRT cells. Biochimica et Biophysica Acta 1354 171-181.

Musti AM, Ursini VM, Avvedimento EV, Zimarino V \& Di Lauro R 1987 A cell type specific factor recognizes the rat thyroglobulin promoter. Nucleic Acids Research 15 8149-8166.

Nagayama Y, Nishihara E, Iitaka M, Namba H, Yamashita S \& Niwa M 1999 Enhanced efficacy of transcriptionally targeted suicide gene/prodrug therapy for thyroid carcinoma with the Cre-loxP system. Cancer Research 59 3049-3052.

Ordonez NG 2000 Thyroid transcription factor-1 is a marker of lung and thyroid carcinomas. Advances in Anatomic Pathology 7 123-127.

Poleev A, Fickenscher H, Mundlos S, Winterpacht A, Zabel B, Fidler A \& Gruss P 1992 Pax8, a human paired-box gene: isolation and expression in developing thyroid, kidney and Wilms' tumors. Development 116 611-623.
Poleev A, Wendler F, Fickenscher H, Zannini M, Yaginuma K, Abbott C \& Plachov D 1995 Distinct functional properties of three human paired-box-protein, Pax8, isoforms generated by alternative splicing in thyroid, kidney and Wilms' tumors. European Fournal of Biochemistry 228 899-911.

Ringel M, Balducci-Silano P, Anderson J, Spencer C, Silverman J, Sparling Y, Francis G, Burman K, Wartofsky L, Ladenson P, Levine M \& Tuttle RM 1999 Quantitative reverse transcription-polymerase chain reaction of circulating thyroglobulin messenger ribonucleic acid for monitoring patients with thyroid carcinoma. Fournal of Clinical Endocrinology and Metabolism 84 4037-4042.

Ros P, Rossi DL, Acebron A \& Santisteban P 1999 Thyroid-specific gene expression in the multi-step process of thyroid carcinogenesis. Biochimie 81 389-396.

Rossi DL, Acebrón A \& Santisteban P 1995 Function of the homeo and paired domain proteins TTF-1 and Pax 8 in thyroid cell proliferation. Fournal of Biological Chemistry 270 23139-23142.

Saiardi A, Tassi V, De Filippis V \& Civitareale D 1995 Cloning and sequence analysis of human thyroid transcription factor 1. Biochimica et Biophysica Acta 1261 307-310.

Schmitt TL, Espinoza CR \& Loos U 2000 Cloning and characterization of repressory and stimulatory DNA sequences upstream the $\mathrm{Na} / \mathrm{I}$-symporter gene promoter. Hormone and Metabolic Research 32 1-5.

Schmitt TL, Espinoza CR \& Loos U 2001 Transcriptional regulation of the human $\mathrm{Na} / \mathrm{I}$-symporter gene by Pax 8 and TTF-1. Experimental and Clinical Endocrinology and Diabetes 109 27-31.

Sinclair AJ, Lonigro R, Civitareale D, Ghibelli L \& Di Lauro R 1990 The tissue-specific expression of the thyroglobulin gene requires interaction between thyroid-specific and ubiquitous factors. European Fournal of Biochemistry 193 311-318.

Zannini M, Francis-Lang H, Plachov D \& Di Lauro R 1992 Pax8, a paired domain-containing protein, binds to a sequence overlapping the recognition site of a homeodomain and activates transcription from two thyroid-specific promoters. Molecular and Cellular Biology 12 4230-4241.

RECEIVED IN FINAL FORM 5 March 2001 ACCEPTED 26 March 2001 